\title{
Chloroquine and hydroxychloroquine in covid-19
}

\author{
Use of these drugs is premature and potentially harmful
}

\author{
Robin E Ferner honorary professor of clinical pharmacology ${ }^{1}$, Jeffrey K Aronson clinical \\ pharmacologist $^{2}$
}

${ }^{1}$ Institute of Clinical Sciences, University of Birmingham, Birmingham, UK; ${ }^{2}$ Centre for Evidence-Based Medicine, Nuffield Department of Primary Care Health Sciences, University of Oxford, Oxford, UK

\begin{abstract}
TheBMJ in 1925 cautiously endorsed Moellgaard's gold treatment for tuberculosis, ${ }^{1}$ although it found his pharmacological reasoning "both interesting and instructive." We should be similarly cautious about proposed treatments for people infected with SARS-CoV-2, the virus that causes covid-19. Many proposals are based on in vitro investigations, studies in experimental animals, or experience with interventions in infections with other viruses, whether similar to SARS-CoV-2 (eg, SARS-CoV-1) or not (HIV).
\end{abstract}

This is all true of chloroquine and hydroxychloroquine, both 4-aminoquinolines, which have been suggested as potential treatments for covid-19. Currently, at least 80 trials of chloroquine, hydroxychloroquine, or both, sometimes in combination with other drugs, are registered worldwide.

The possible activity of 4-aminoquinolines in infectious mononucleosis was first proposed in 1960, before its viral cause was known. ${ }^{3}$ Several unsatisfactory clinical trials followed, some with positive results and some negative. In 1967 the authors of a small but well conducted randomised, double blind, placebo controlled trial of chloroquine concluded that "except for supportive measures, infectious mononucleosis is essentially untreatable." ${ }^{4}$

Since then, many studies have shown that 4-aminoquinolines are active in vitro against a range of viruses. Their efficacy has been attributed to different mechanisms. For example, they are weak bases and increase endosomal $\mathrm{pH}$ in host intracellular organelles, inhibiting autophagosome-lysosome fusion and inactivating enzymes that viruses require for replication. ${ }^{5}$ They may also affect glycosylation of angiotensin converting enzyme-2, the receptor that SARS-CoV-2 uses to enter cells. ${ }^{6}$

\section{Laboratory studies}

In cell cultures and animal studies, the effects of 4-aminoquinolines on viruses from avian influenza virus $(\mathrm{H} 5 \mathrm{~N} 1)^{7}$ to $\mathrm{Zika}^{8}$ have been variable. In cells infected by Epstein-Barr virus, for example, chloroquine increased viral replication. ${ }^{9}$ In one study, chloroquine reduced transmission of Zika virus to the offspring of five infected mice. ${ }^{10}$ Chloroquine inhibited Ebola virus replication in vitro but caused rapid worsening of Ebola infection in guinea pigs ${ }^{11}$ and made no difference to mortality in mice and hamsters. ${ }^{12}$ In chikungunya virus infection, chloroquine was active in laboratory studies but worsened the clinical course of infection in macaque monkeys. ${ }^{13}$

The translation from laboratory to clinic has also led to disappointments. For example, chloroquine inhibited dengue virus in some cell cultures ${ }^{14}$ but failed to shorten the illness in a randomised study of 37 patients. ${ }^{15}$ And although laboratory studies suggested activity against influenza virus, chloroquine did not prevent infection in a large randomised trial. ${ }^{16}$ The disparity between laboratory and clinical experiments may be partly due to the complex pharmacokinetics of 4-aminoquinolines, ${ }^{17}$ making it difficult to extrapolate from concentrations in culture media to doses in humans. ${ }^{18}$

\section{Poor methods and reporting}

Hydroxychloroquine and chloroquine inhibit SARS-CoV-2 in vitro, and a Chinese commentary, mentioning 15 trials, reported that, "Thus far, results from more than 100 patients have demonstrated that chloroquine phosphate is superior to the control treatment in inhibiting the exacerbation of pneumonia," 19 without giving any further details. A preliminary account of one of those trials, a placebo controlled randomised study of two different doses of hydroxychloroquine in 62 patients with radiological findings of pneumonia but without severe hypoxia, reported small improvements in body temperature and cough in the higher dose treatment group. ${ }^{20}$ However, the endpoints specified in the published protocol differed from those reported, the results in the low dose group were not described, and the trial seems to have been stopped prematurely. ${ }^{21}$

An open, non-randomised study of hydroxychloroquine, published in preprint, reportedly supported efficacy in 20 patients, but the trial design was poor and the results unreliable: six patients dropped out of the treatment arm (two because of admission to an intensive care unit and one because he died); the measure of efficacy was viral load, not a clinical endpoint; and assessments were made on day 6 after starting treatment. ${ }^{22}$ 
Advocates, including Donald Trump, have argued that hydroxychloroquine is widely used and safe. Its use is now permitted by the US Food and Drug Administration ${ }^{23}$ and advocated by the Indian Council for Medical Research. ${ }^{24}$ But no drug is guaranteed to be safe, and wide use of hydroxychloroquine will expose some patients to rare but potentially fatal harms, including serious cutaneous adverse reactions, ${ }^{25}$ fulminant hepatic failure, ${ }^{26}$ and ventricular arrhythmias (especially when prescribed with azithromycin) ${ }^{27}$; overdose is hazardous and difficult to treat. ${ }^{28}$

We sorely need an effective treatment for covid-19, but prevention by a vaccine or treatment with drugs that target specific structures in the virus are more likely to succeed than old drugs that may work in the laboratory but lack data supporting clinical use. No intervention should be assumed to be efficacious. Even drugs initially supported by evidence of effectiveness may later prove to be more harmful than beneficial. Too many medicines have been withdrawn because of adverse reactions after showing clinical promise. ${ }^{29}$ We need better, properly powered, randomised controlled trials of chloroquine or hydroxychloroquine. For now, except for supportive measures, infection with SARS-CoV-2 is "essentially untreatable."

We thank Patricia McGettigan for her help with this article.

Competing interests: JKA is a member of the Centre for Evidence-Based Medicine in Oxford, which jointly runs the EvidenceLive Conference with the BMJ and the Overdiagnosis Conference with some international partners, which are based on a non-profit model. $\mathrm{He}$ is an associate editor of BMJ Evidence Based Medicine and was until recently vice-president publications for the British Pharmacological Society. REF was until recently a member of the Birmingham, Sandwell and Solihull Area prescribing committee, is a series editor of The BMSS Therapeutic Series, and has an honorary position at University College London.

Provenance and peer review: Commissioned; not externally peer reviewed.

1 Moellgaard $\mathrm{H}$. The theoretical basis of the sanocrysin treatment of tuberculosis. $\mathrm{Br} \mathrm{Med}$ $J$ 1925:1:643-47. 10.1136/bmj.1.3353.643 20771993

2 The gold treatment of tuberculosis. Br Med J 1925;1:668. https://www.ncbi.nlm.nih.gov/ pmc/articles/PMC2226411/pdf/brmedj05703-0025.pdf20772016

3 Gothberg LA. Severe infectious mononucleosis treated with chloroquine phosphate. $J$ Am Med Assoc 1960;173:53-7. 10.1001/jama.1960.73020190016012 13851408

4 Updike SJ, Eichman PL. Infectious mononucleosis treated with chloroquine. A double-blind study of 40 cases. Am J Med Sci 1967;254:69-70.

10.1097/00000441-196707000-00008 6027689

5 Salata C, Calistri A, Parolin C, Baritussio A, Palù G. Antiviral activity of cationic amphiphilic drugs. Expert Rev Anti Infect Ther 2017;15:483-92. 10.1080/14787210.2017.1305888 28286997

6 Vincent MJ, Bergeron E, Benjannet S, etal . Chloroquine is a potent inhibitor of SARS coronavirus infection and spread. Virol J 2005;2:69. 10.1186/1743-422X-2-69 16115318

7 Yan Y, Zou Z, Sun Y, etal . Anti-malaria drug chloroquine is highly effective in treating avian influenza A H5N1 virus infection in an animal model. Cell Res 2013;23:300-2. $10.1038 /$ cr.2012.165 23208422
8 Shiryaev SA, Mesci P, Pinto A, etal . Repurposing of the anti-malaria drug chloroquine for Zika Virus treatment and prophylaxis. Sci Rep 2017;7:15771.

10.1038/s41598-017-15467-6 29150641

9 Li X, Burton EM, Bhaduri-McIntosh S. Chloroquine triggers Epstein-Barr virus replication through phosphorylation of KAP1/TRIM28 in Burkitt lymphoma cells. PLoS Pathog 2017;13:e1006249. 10.1371/journal.ppat.1006249 28249048

10 Li C, Zhu X, Ji X, etal . Chloroquine, a FDA-approved drug, prevents Zika virus infection and its associated congenital microcephaly in mice. EBioMedicine 2017;24:189-94. 10.1016/j.ebiom.2017.09.034 29033372

11 Dowall SD, Bosworth A, Watson R, etal . Chloroquine inhibited Ebola virus replication in vitro but failed to protect against infection and disease in the in vivo guinea pig model. $J$ Gen Virol 2015;96:3484-92. 10.1099/jgv.0.00030926459826

12 Falzarano D, Safronetz D, Prescott J, Marzi A, Feldmann F, Feldmann H. Lack of protection against ebola virus from chloroquine in mice and hamsters. Emerg Infect Dis 2015;21:1065-7. 10.3201/eid2106.15017625988934

13 Roques P, Thiberville SD, Dupuis-Maguiraga L, etal . Paradoxical effect of chloroquine treatment in enhancing chikungunya virus infection. Viruses 2018;10:268. 10.3390/v10050268 29772762

14 Wang LF, Lin YS, Huang NC, etal . Hydroxychloroquine-inhibited dengue virus is associated with host defense machinery. J Interferon Cytokine Res 2015;35:143-56. 10.1089/jir.2014.0038 25321315

15 Borges MC, Castro LA, Fonseca BA. Chloroquine use improves dengue-related symptoms. Mem Inst Oswaldo Cruz 2013;108:596-9. 10.1590/S0074-02762013000500010 23903975

16 Paton NI, Lee L, Xu Y, etal . Chloroquine for influenza prevention: a randomised, double-blind, placebo controlled trial. Lancet Infect Dis 2011;11:677-83. 10.1016/S1473-3099(11)70065-2 21550310

17 Gustafsson LL, Walker O, Alván G, etal . Disposition of chloroquine in man after single intravenous and oral doses. Br J Clin Pharmacol 1983;15:471-9. 10.1111/j.1365-2125.1983.tb01532.x 6849784

18 Akpovwa $\mathrm{H}$. Chloroquine could be used for the treatment of filoviral infections and other viral infections that emerge or emerged from viruses requiring an acidic $\mathrm{pH}$ for infectivity. Cell Biochem Funct 2016;34:191-6. 10.1002/cbf.3182 27001679

19 Gao J, Tian Z, Yang X. Breakthrough: chloroquine phosphate has shown apparent efficacy in treatment of COVID-19 associated pneumonia in clinical studies. Biosci Trends 2020;14:72-3. 10.5582/bst.2020.01047 32074550

20 Chen Z, Hu J, Zhang Z, et al. Efficacy of hydroxychloroquine in patients with COVID-19: results of a randomized clinical trial. Version 2. medRxiv 2020.03.22.20040758. [Preprint.] 10.1101/2020.03.22.20040758

21 Yan $D$, Zhang Z. Therapeutic effect of hydroxychloroquine on novel coronavirus pneumonia (COVID-19). Chinese Clinical Trials Registry. http://www.chictr.org.cn/showproj.aspx? proj $=48880$

22 Gautret $\mathrm{P}$, Lagier JC, Parola $\mathrm{P}$, etal . Hydroxychloroquine and azithromycin as a treatment of COVID-19: results of an open-label non-randomized clinical trial. Int J Antimicrob Agents 2020:105949. 10.1016/j.jijantimicag.2020.105949 32205204

23 Lenzer J. Covid-19: US gives emergency approval to hydroxychloroquine despite lack of evidence. BMJ 2020;369:m1335. 10.1136/bmj.m1335 32238355

24 Indian Council for Medical Research. Recommendation for empiric use of hydroxychloroquine for prophylaxis of SARS-CoV-2 infection. https://icmr.nic.in/sites/ default/files/upload_documents/HCQ_Recommendation_22March_final_MM_V2.pdf. Accessed 3 April 2020.

25 Murphy M, Carmichael AJ. Fatal toxic epidermal necrolysis associated with hydroxychloroquine. Clin Exp Dermatol 2001;26:457-8. 10.1046/j.1365-2230.2001.00857-3.x 11488840

26 Makin AJ, Wendon J, Fitt S, Portmann BC, Williams R. Fulminant hepatic failure secondary to hydroxychloroquine. Gut 1994;35:569-70. 10.1136/gut.35.4.569 8175002

27 Chorin E, Dai M, Shulman E, et al. The QT interval in patients with SARS-CoV-2 infection treated with hydroxychloroquine/azithromycin. medRxiv 2020.04.02.20047050. [Preprint] 10.1101/2020.04.02.20047050v1

28 Gunja N, Roberts D, McCoubrie D, etal . Survival after massive hydroxychloroquine overdose. Anaesth Intensive Care 2009;37:130-3. 10.1177/0310057X0903700112 19157361

29 Onakpoya IJ, Heneghan CJ, Aronson JK. Post-marketing withdrawal of 462 medicinal products because of adverse drug reactions: a systematic review of the world literature. BMC Med 2016;14:10. 10.1186/s12916-016-0553-2 26843061

Published by the BMJ Publishing Group Limited. For permission to use (where not already granted under a licence) please go to http://group.bmj.com/group/rights-licensing/ permissions 